\title{
On the Seismic Response of Protected and Unprotected Middle-Rise Steel Frames in Far-Field and Near-Field Areas
}

\author{
Dora Foti \\ Department of Civil Engineering and Architecture, Polytechnic of Bari, 70125 Bari, Italy \\ Correspondence should be addressed to Dora Foti; d.foti@poliba.it
}

Received 28 February 2014; Revised 1 June 2014; Accepted 4 June 2014; Published 15 July 2014

Academic Editor: Vadim V. Silberschmidt

Copyright (C) 2014 Dora Foti. This is an open access article distributed under the Creative Commons Attribution License, which permits unrestricted use, distribution, and reproduction in any medium, provided the original work is properly cited.

\begin{abstract}
Several steel moment-resisting framed buildings were seriously damaged during Northridge (1994); Kobe (1995); Kocaeli, Turkey (1999), earthquakes. Indeed, for all these cases, the earthquake source was located under the urban area and most victims were in near-field areas. In fact near-field ground motions show velocity and displacement peaks higher than far-field ones. Therefore, the importance of considering near-field ground motion effects in the seismic design of structures is clear. This study analyzes the seismic response of five-story steel moment-resisting frames subjected to Loma Prieta (1989) earthquake-Gilroy (far-field) register and Santa Cruz (near-field) register. The design of the frames verifies all the resistance and stability Eurocodes' requirements and the first mode has been determined from previous shaking-table tests. In the frames two diagonal braces are installed in different positions. Therefore, ten cases with different periods are considered. Also, friction dampers are installed in substitution of the braces. The behaviour of the braced models under the far-field and the near-field records is analysed. The responses of the aforementioned frames equipped with friction dampers and subjected to the same ground motions are discussed. The maximum response of the examined model structures with and without passive dampers is analysed in terms of damage indices, acceleration amplification, base shear, and interstory drifts.
\end{abstract}

\section{Introduction}

Recent destructive earthquakes in Northridge (1994); Kobe (1995); Kocaeli, Turkey (1999); and Chi-Chi, Taiwan (1999) caused great impact on society due to the relevant number of collapsed buildings and victims. Indeed, for all these cases, the earthquake source was located under the urban area. Moreover, it must be underlined that most earthquake victims were in near-field areas, that is, in the immediate vicinity of the epicentral zone. In particular, it must be noticed that if the station is located toward the direction of the fault rupture, the near-field ground motions are quite different from the usual far-field ones. In fact, in near-field areas, the normal-fault component of the ground motion is a pulse-type one, with a long-period pulse in the acceleration time history. Such a pronounced pulse does not exist in ground motions recorded at locations away from the nearfield region. Therefore, the importance of considering nearfield ground motion effects in the seismic design of structures is clear. On the contrary, the seismic codes deal with problems and design procedures related to far-field or intermediate epicentral distances, where the characteristics of the ground motion are better documented and more studied.

Simple deterministic and probabilistic models for nearfield pulse-like ground motions that account for nonstationarity and multiple pulses in the velocity signal have been developed with the aim to examine the implication of this class of ground motions on the response of structures $[1,2]$.

Examining the failure modes of steel MRFs in nearfield areas after the strong earthquakes mentioned above, the scientists observed that, in many cases, damage arose also when both design and detailing have been performed in perfect accordance with the code provisions. This means that something new happened, which was not foreseen in the design practice. As a consequence, it is possible to underline new important aspects consisting in differences between ground motions and structural behaviour in near-field and in far-field areas [3-6].

These problems could occur also for small and moderate magnitude earthquakes. In fact, during an earthquake such 
as San Salvador 1986 earthquake, in near-field regions, the ground motion can be particularly severe [7].

To get better knowledge on near-field ground motions, well-known concepts and results obtained from far-field motions have been extended to near-field ones. Comparisons of the responses of SDF systems subjected to the two mentioned motions have been developed, based on elastic and inelastic response spectra $[8,9]$.

In addition, a drift spectrum has been developed and the elastic response of structures to near- and far-field ground motions has been determined. In fact, the drift spectrum provides important information to near-field ground motions that cannot be obtained from the response spectrum. Anyway, the drift spectrum seems to be restricted to structures that can be idealized as a shear beam [10].

The building strength appropriate for near-field ground motion is investigated in [11]. Six-story and 20-story steelframe buildings designed according to UBC-94 and the Japanese Code have been considered. In this research, the analyses have been performed including structure degradation effects on welded connections. The strong and short buildings have shown the best behaviour under large nearfield earthquakes.

Nonlinear dynamic analyses have been also performed on a 6-story moment-resisting frame protected with friction and viscous damping systems. A parametric study has been developed and the brittleness of welded beam-to-column connections has been considered by introducing a flexural strength degradation model. The friction and viscous systems can significantly reduce the response of the structure under near-field ground motions but do not prevent the fracture of the beam-to-column joints [12].

To acquire quantitative knowledge on near-field ground motion effects based on the procedure of equivalent velocity pulses, artificial accelerograms have been generated and a comparison between the response of structures to near-field ground motions and to equivalent pulses motions has been provided. The results show the complexity of near-field effects and the necessity of experimental investigation [13].

The analysis has been also performed on middle-rise steel frames subjected to near-field ground motions, which expose the structures to higher ductility demands than the far- or intermediate-field ground motions. When the structure is relatively stiffer, the distribution of the shear forces along the height of the structure is higher at the upper stories. This behaviour is caused by the early yielding developed at the upper floors. When the frame has a reduced stiffness the maximum ductility demand migrates from the upper part to the base. To significantly reduce the maximum ductility demand and to avoid the failure, the strength of the upper portion of slender frames must be increased (keeping the column cross section constant along the total height of the structure).

This new aspect has been emphasised in the response of frames equipped with friction dampers [14]. A frame without any of these devices absorbs itself most of the input energy and is subjected to large accelerations and interstory drifts. On the contrary, a protected frame is kept in the elastic range and the plastic deformations are concentrated in the dissipaters, which can be easily replaced after an earthquake $[15,16]$.

The responses of the aforementioned frames equipped with friction dampers and subjected to the same earthquake recorded in far-field and in near-field regions are discussed. Although the passive damping systems can reduce significantly the response of the moment-resisting frame structures under near-field motions, they cannot by themselves prevent the collapse. Anyway, these systems could be a solution to avoid story mechanism. Nevertheless, in some cases, the interstory drifts do not satisfy the code recommendations, but specific design criteria for structures in near-field areas need to be performed [17]. The dissipating devices utilized have a behaviour similar to the one described in [18]. Studies have also been developed on base isolated buildings under impulsive motion without and with a seismic base isolation system combined or not with supplemental passive dampers [19-22].

In the present study the seismic response of five-story steel moment-resisting frames subjected to Loma Prieta (1989) earthquake, a far-field register and a near-field register, is analysed. The design of the frames verifies all the resistance and stability Eurocodes' requirements and the first mode has been determined from previous shaking-table tests. The node connections are kept rigid but can rotate; the rotation stiffness was identified from a series of shaking-table tests on a steel model. The results from the experimental tests gave the possibility to update a preliminary experimental model that is good to perform the numerical analyses performed in this research. In the numerical analysis of the steel frame two diagonal braces are installed in different positions. Therefore, ten cases with different periods are considered. Also, friction dampers are installed in substitution of the braces.

The responses of the frames with and without friction dampers and subjected to the same aforementioned ground motions are also discussed.

The maximum response of the examined model structures with and without passive dampers is discussed in terms of damage indices, acceleration amplification, base shear, and interstory drifts.

\section{Description of the Frames}

A model utilized in a previous series of shaking-table tests has been adopted as model for the present numerical analysis. The model is a 3D steel moment-resisting frame with 5 levels with a total height of $170 \mathrm{~cm}$. Along one direction there are two bays and in the other direction there is one.

The models have been equipped with two diagonal braces installed in different positions. The aim is to determine the position of the braces, which gives the best seismic response of the model.

The node connections are kept rigid but can rotate; the rotation stiffness was determined from a series of shakingtable tests on a steel model (Figure 1) [23, 24].

The analysis has also been performed considering friction dampers similar to those shown in Figure 2. They have been designed and built as described in $[23,24]$. The friction 


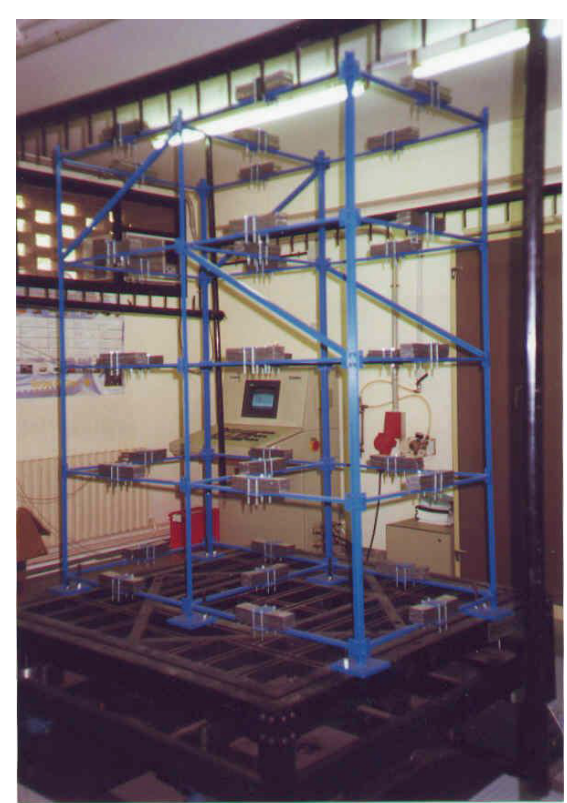

(a)

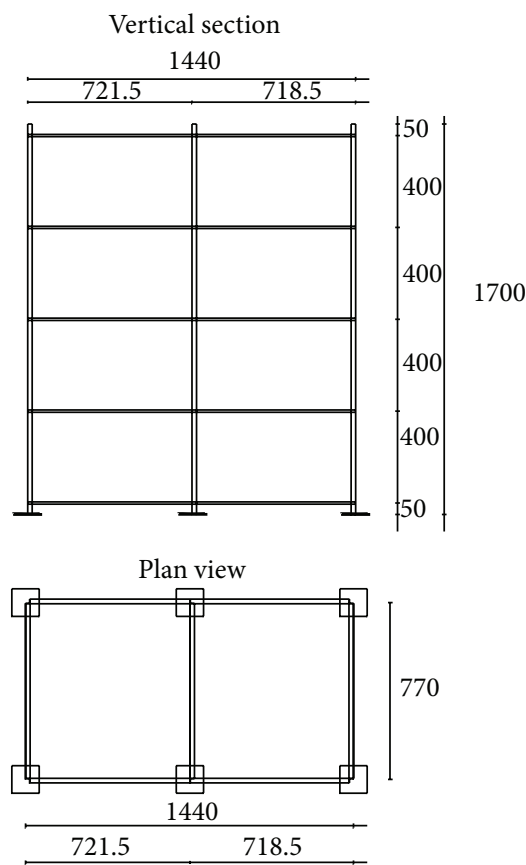

(b)

FIgURE 1: The steel model of the previous shaking-table tests.

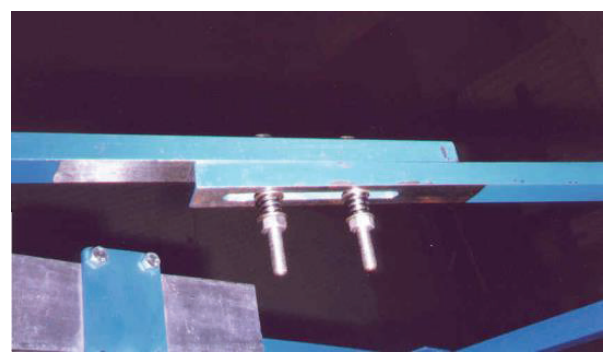

(a)

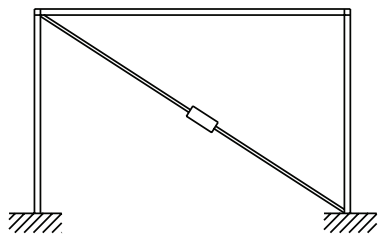

(b)

FIgURE 2: Friction damper utilized in the dynamic tests. (a) Detail of the dissipation node. (b) Force-displacement $(F-\delta)$ diagram.

dampers dissipate energy through steel-steel friction when the structure undergoes interstory drifts. Basically two parts of a brace with slotted holes are connected by high strength bolts. Its $F-\delta$ behavior is a rigid-perfect plastic one with a wide hysteresis cycle and, consequently, high energy dissipation.

The friction dampers have been installed in substitution of the diagonals to compare the results obtained in both cases of protected and unprotected models.

Figure 3 shows the ten cases considered in the analysis. The objective was to numerically determine the position of the diagonals and, consequently, of the dampers to obtain the best seismic response of the structure during an earthquake.

In Table 1 the natural periods of each case model are shown.

Another model without braces and dissipaters is the socalled bare frame. It will be considered in the analysis for comparison purposes.

The numerical analysis has been performed with a finite element program, which considers the frame in the linear field while nonlinearities are concentrated only in the dissipaters [25]. The yielding force of the friction devices has been considered equal to $75 \%$ of the maximum force obtained under an equivalent horizontal static load [26].

\section{Ground Motions}

Loma Prieta 1989 earthquake has been chosen for the analyses of the models. More in detail Lick Observatory $90^{\circ}$ record (LOMA_P1) and Bolsa Rd. $90^{\circ}$ record (LOMA_P2) have been considered. The first record, LOMA_P1, has been determined at a station $18.8 \mathrm{Km}$ far away from the fault. The acceleration time-history plot does not show an impulsive behavior. Therefore, with a good approximation, it corresponds to a far-field record. The second record, LOMA_P2, has been determined at a station $4.5 \mathrm{Km}$ far away from the fault. Therefore it could be assumed as a near-field record. Figure 4 shows the acceleration time histories of the two registers; 


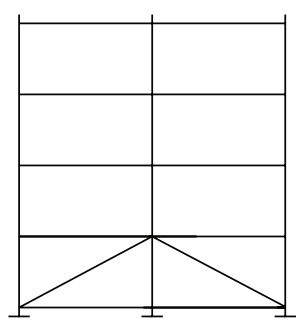

Case 1
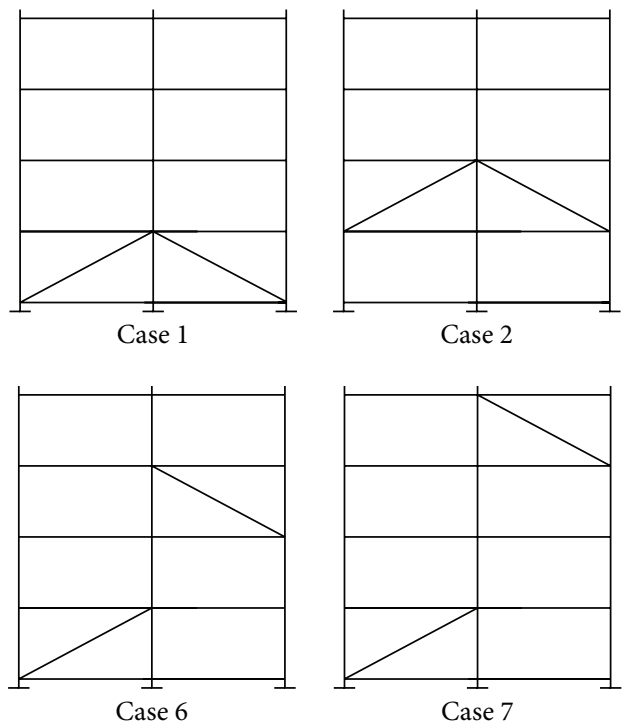

Case 2

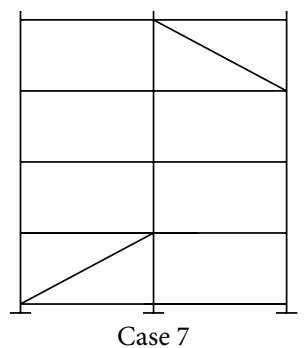

Case 7

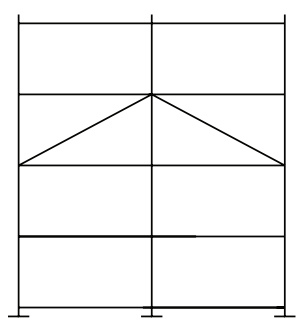

Case 3

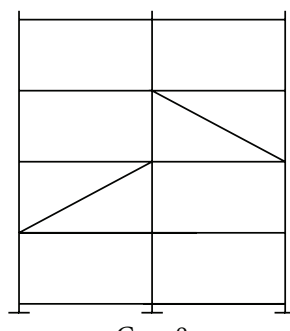

Case 8

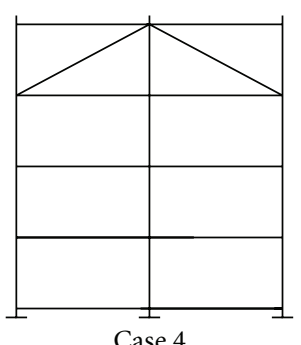

Case 4

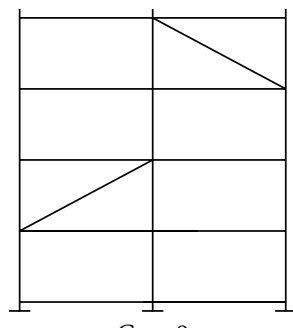

Case 9

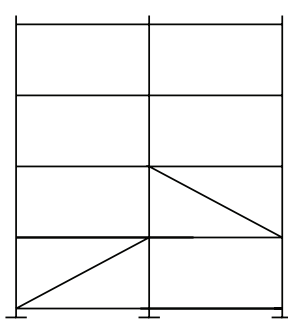

Case 5

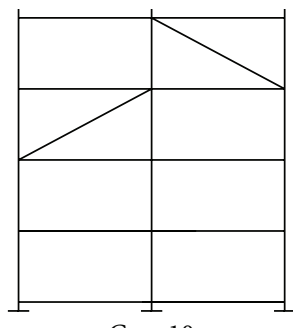

Case 10

FIgURE 3: Models of the frames corresponding to the cases 1, 2, 3, 4, 5, 6, 7, 8, 9, and 10.

TABLE 1: Natural periods of the ten models.

\begin{tabular}{lccccccccccc}
\hline Frames & Case 1 & Case 2 & Case 3 & Case 4 & Case 5 & Case 6 & Case 7 & Case 8 & Case 9 & Case 10 \\
\hline$T(\mathrm{~s})$ & 0.302 & 0.2217 & 0.2835 & 0.3653 & 0.1988 & 0.1498 & 0.2421 & 0.1679 & 0.174 & 0.2822 \\
\hline
\end{tabular}

Figure 5 shows the corresponding elastic response spectra in the range $[0-1 \mathrm{~s}]$.

The two registers have been scaled with respect to the maximum acceleration of LOMA_P1.

\section{Results}

SadSap software has been utilised for the numerical analyses [25].

The results are given in terms of global damage indices, maximum amplification, and maximum interstory drifts.

The global damage index is defined as the ratio of the top displacement $D$ on the total height of the structure $H$.

In all the responses the 1st level is neglected as it is very close to the base.

4.1. Far-Field Ground Motion (LOMA_P1). Comparisons of the responses for braced and protected frames are as follows.

(i) Maximum Interstory Drifts. The maximum interstory drift is always higher in the protected frames except in case 1 (4th and 5 th levels) and in case 3 (2nd level).

(ii) Maximum Base Shear. The maximum base shear, as expected, is always lower in the protected frames except for cases 4,5 , and 7 .

(iii) Global Damage Index. The global damage index, as expected due to the higher displacements, is always higher in the protected frames. (iv) Maximum Absolute Acceleration. The maximum absolute acceleration is higher in the protected frames for cases 4 and 7.

(v) Response Amplification. The maximum absolute acceleration versus the maximum ground acceleration, has been evaluated as response amplification. This value has been determined at each level. The amplification values increase from the base to the top level.

The values are always higher in the braced frames, except in the following:

case 1 at the 2nd and 3rd levels;

case 2 at the 4 th level;

case 4 at the 5 th level;

case 5 at the 4 th, $3 \mathrm{rd}$, and 2 nd levels;

case 6 at the 2 nd level;

case 7 at the 5th, 4 th, 3rd, and 2nd levels;

case 11 at the 2 nd level.

(vi) Energy Dissipation. The maximum energy dissipation produced by the friction dampers is obtained in case $3\left(T_{3}=\right.$ $0.28347 \mathrm{~s}$ ), while the minimum energy dissipation is obtained in case $1\left(T_{1}=0.30199 \mathrm{~s}\right)$.

Bare Frame. The frame shows lower values of the global damage index and the interstory drift if compared to the protected frames. Moreover the acceleration amplifications are higher in the bare frame at the 2 nd level with respect to all the protected frames. 


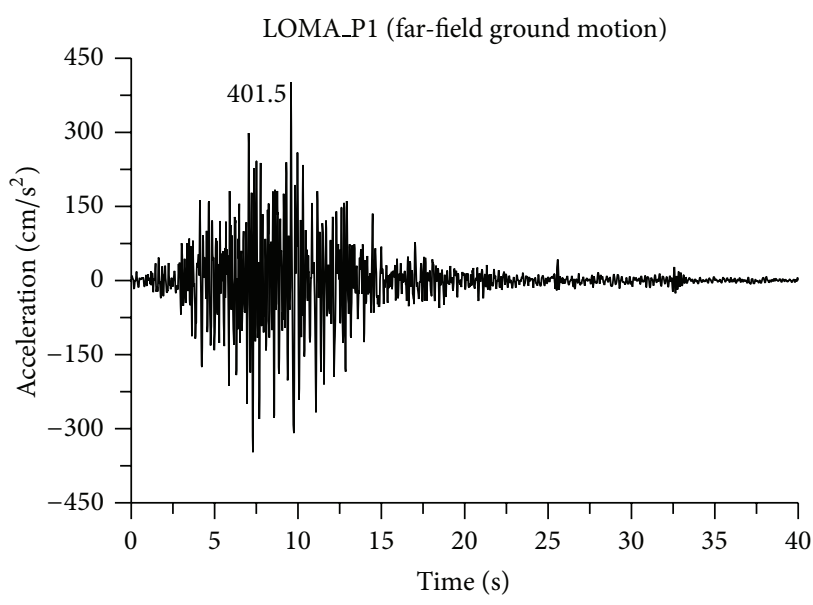

(a)

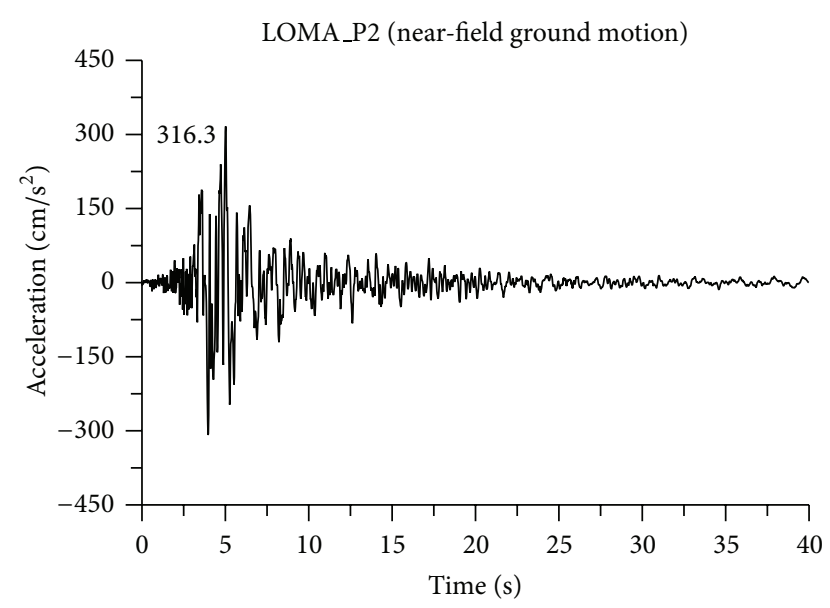

(b)

FIGURE 4: Acceleration time histories of (a) LOMA_P1 (FF) and (b) LOMA_P2 (NF) records.

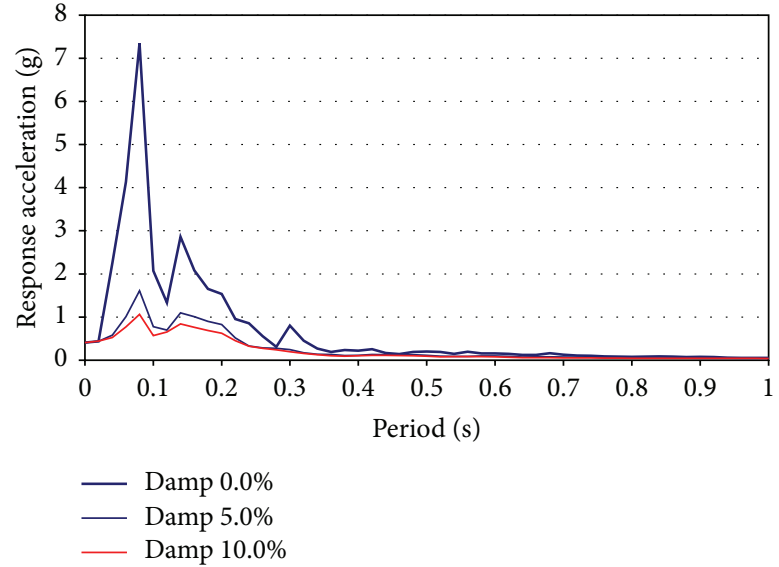

(a)

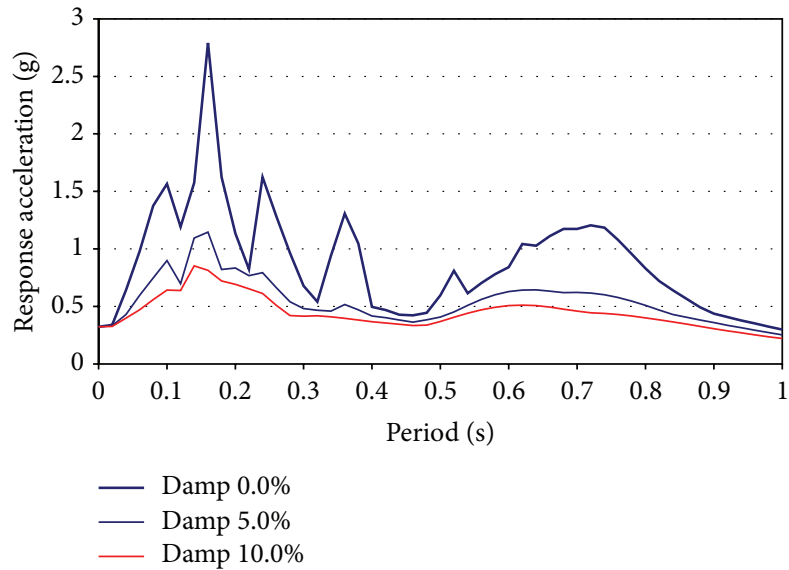

(b)

FIGURE 5: Elastic response spectrum of (a) LOMA_P1 (FF) and (b) LOMA_P2 (NF) records.

4.2. Near-Field Ground Motion (LOMA_P2). Comparisons of the responses for braced and protected frames are as follows.

(i) Maximum Interstory Drifts. The maximum interstory drift is always higher in the protected frames except in case 1 (4th and 5th levels), case 3 (2nd level), and case 4 (2nd level).

(ii) Maximum Base Shear. The maximum base shear, as expected, is always lower in the protected frames except for case 5 and case 7 .

(iii) Global Damage Index. The global damage index, as expected due to the higher displacements, is always higher in the protected frames.

(iv) Maximum Absolute Acceleration. The maximum absolute acceleration is higher in the protected frames for cases 4,7 , and 8 . (v) Response Amplification. The maximum absolute acceleration, versus the maximum ground acceleration, has been evaluated as response amplification. This value has been determined at each level. The amplification values increase from the base to the top level.

The values are always higher in the braced frames, except in the following:

case 1 at the 2 nd level;

case 2 at the 3 rd and 4 th levels;

case 4 at the 5 th level;

case 5 at the 2 nd, 3 rd, and 4 th levels;

case 6 at the 2nd and 4th levels;

case 7 at the 2nd, 3rd, 4th, and 5th levels; 

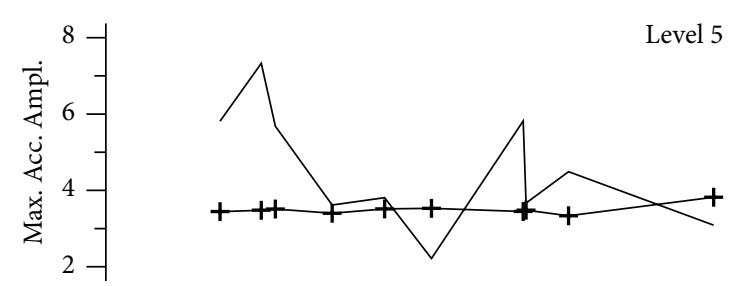

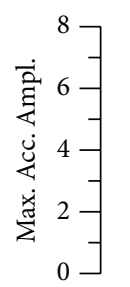

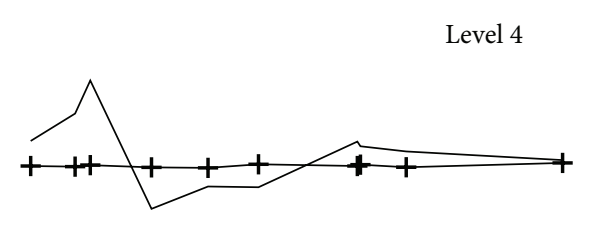

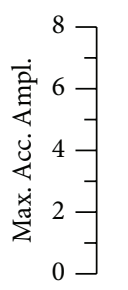

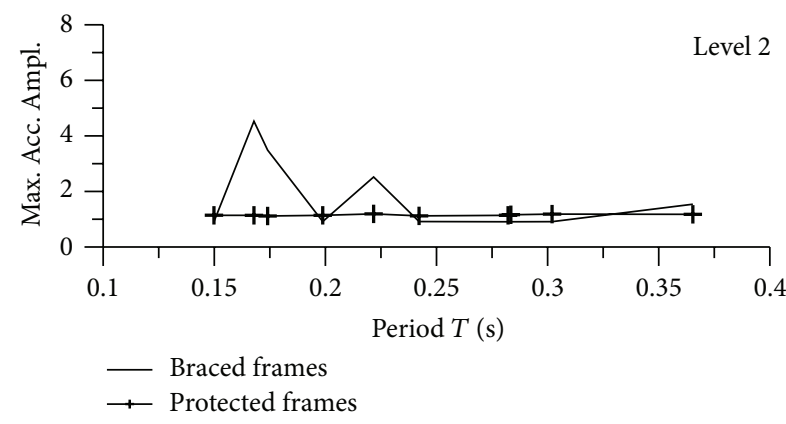

(a) LOMA_P1 (FF)
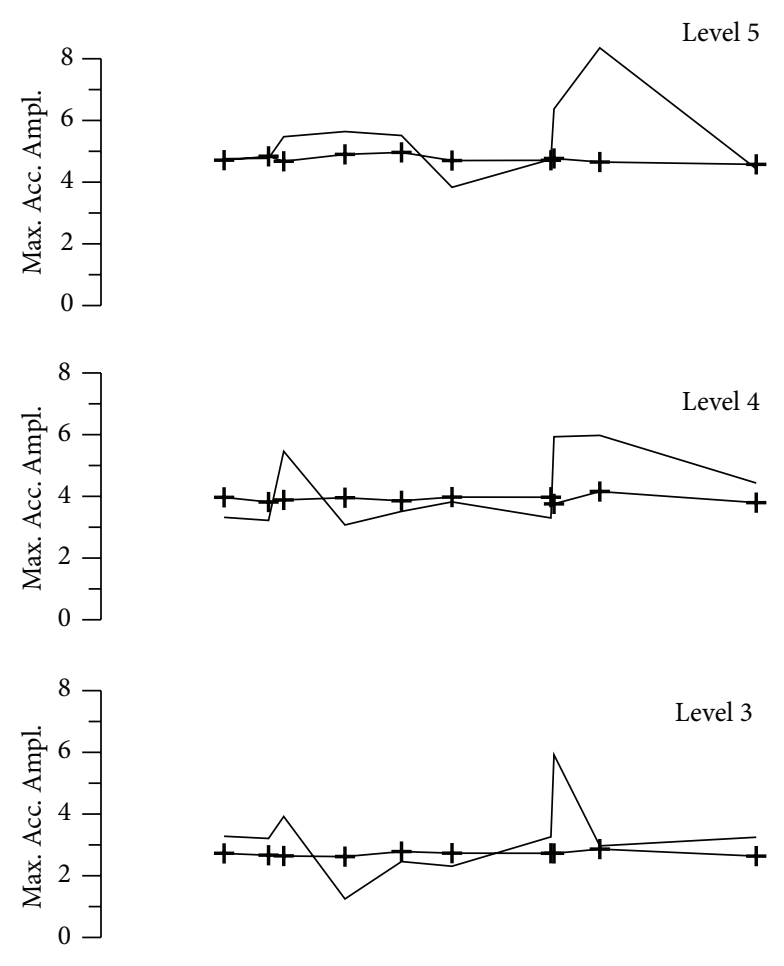

Level 3

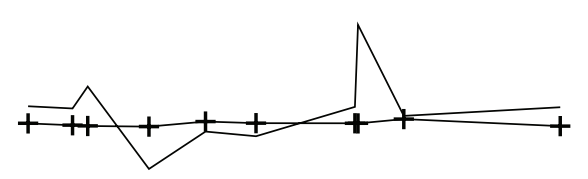

Level 2

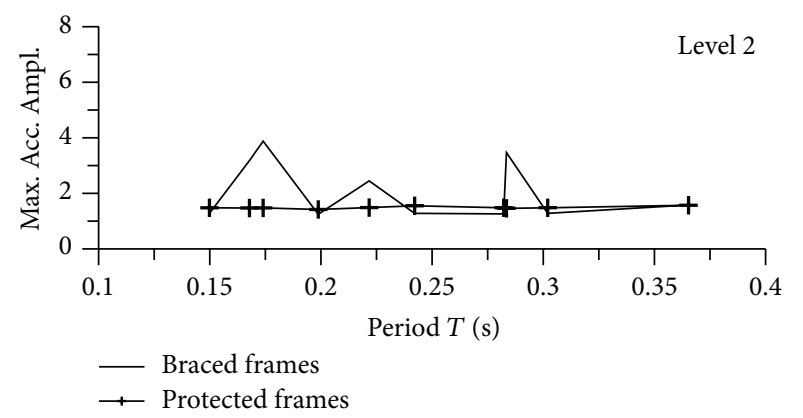

(b) LOMA_P2 (NF)

Figure 6: Maximum amplification for the 10 frames subjected to (a) LOMA_P1 (FF) record and to (b) LOMA_P2 (NF) record.

case 8 at the 4 th and 5 th levels;

case 10 at the 2 nd and 4 th levels.

(vi) Energy Dissipation. The maximum energy dissipation produced by the friction dampers is obtained in case $2\left(T_{2}=\right.$ $0.22172 \mathrm{~s}$ ), while the minimum energy dissipation is obtained in case $7\left(T_{7}=0.24213 \mathrm{~s}\right)$.

In Figure 6 the maximum acceleration amplifications of the braced and protected frames under LOMA_P1 (far-field ground motion) and LOMA_P2 (near-field ground motion) are shown. The responses are evaluated at each level, except the 1st one.

From all the results in Sections 4.1 and 4.2 it appears that case $5\left(T_{5}=0.1988 \mathrm{~s}\right)$ and case $7\left(T_{7}=0.24213 \mathrm{~s}\right)$ have a worse behaviour if equipped with friction dampers.

Bare Frame. The frame shows lower values of the global damage index and the interstory drifts if compared to the protected frames. Moreover the acceleration amplifications are mostly higher in the bare frame and at the 3rd and 2nd levels they are higher with respect to all the protected frames.

\subsection{Far-Field (LOMA_P1) and Near-Field (LOMA_P2) Ground Motions. Comparison of the responses is as follows.}

\section{(i) Maximum Interstory Drifts}

Braced Frames. The maximum displacement is higher for the frames subjected to near-field ground motions except for cases $6,8,9$, and 10 .

Protected Frames. The maximum displacement is always higher for the frames subjected to near-field ground motions.

In Figure 7 the maximum interstory drifts for case 6 (low period frame), case 7 (medium period frame), and case 4 (high period frame) are shown. 

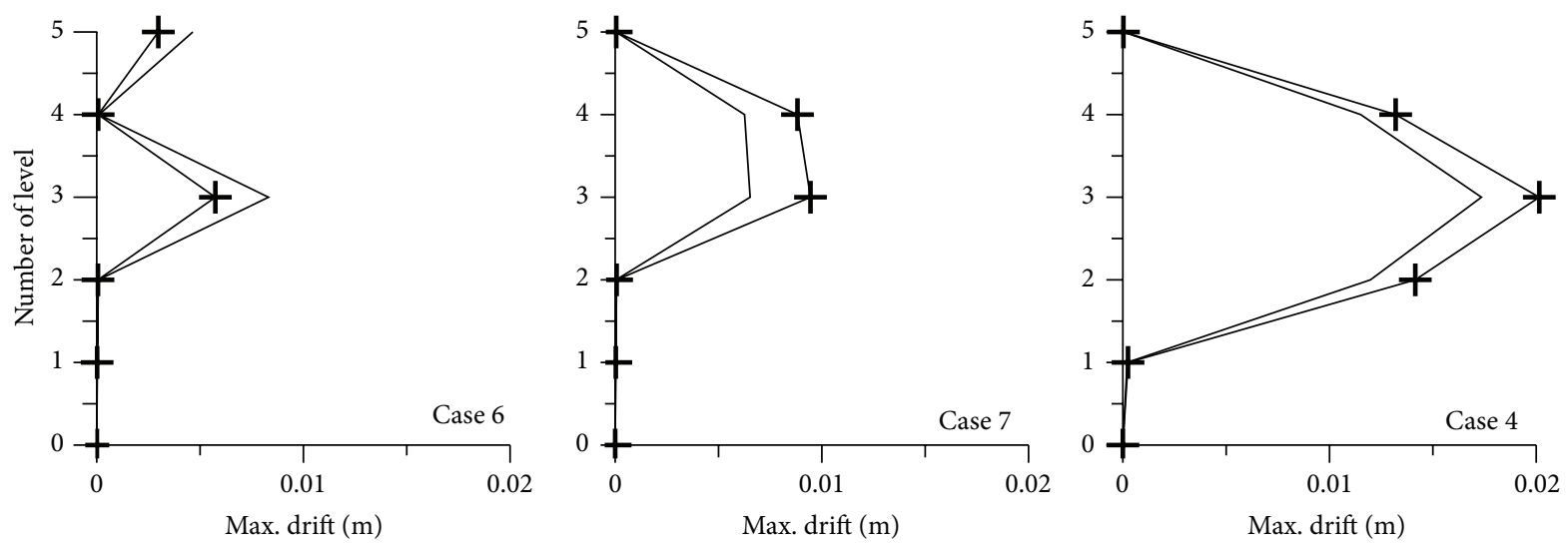

(a) Braced frames
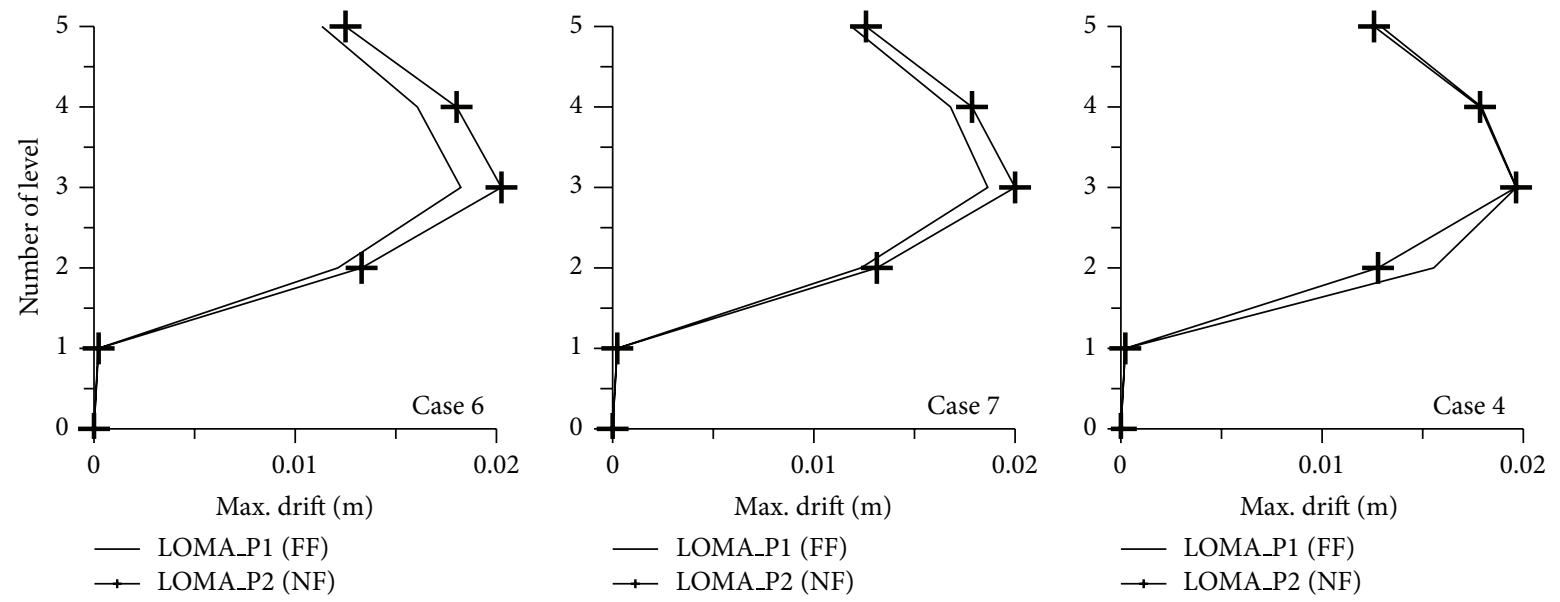

(b) Protected frames

FIgURE 7: Maximum interstory drift for cases 6, 7, and 4.

\section{(ii) Maximum Base Shear}

Braced Frames. The maximum base shear is higher for structures in near-field areas except for cases 6, 8, 9, and 10.

Protected Frames. The maximum base shear is always higher in the frames subjected to near-field ground motions with respect to those subjected to far-field ones.

For the bare frames the values of the maximum base shear/Wtot are always higher if referred to the protected near-field frames. In case of far-field frames the value of the maximum base shear for the bare frame is always lower than that for the protected frames (Figure 8).

\section{(iii) Global Damage Index}

Braced Frames. The global damage index is always higher in the frames subjected to near-field ground motions except for cases $6,8,9$, and 10 . There is a high increment for high period frames.

Protected Frames. The global damage index is higher in the frames under near-field motions for all the cases.
In Figure 9 the global damage indices for the braced frames and the protected frames are shown.

\section{(iv) Maximum Absolute Acceleration}

Braced Frames. The value of the maximum absolute acceleration is higher in near-field frames except for cases 6,8 , 9, and 10.

Protected Frames. The maximum absolute acceleration is higher in the near-field frames except for case 4 . In fact farfield ground motions excite the high frequencies of the frames more than the near-field motions do.

(v) Response Amplification. The maximum absolute acceleration, versus the maximum ground acceleration, has been evaluated as response amplification. This value has been determined at each level. The amplification values increase from the base to the top level.

Braced Frames. The amplification is higher for the frames subjected to near-field records except for the following:

case 6 at the 3rd, 4th, and 5th levels;

case 8 at the $2 \mathrm{nd}, 3 \mathrm{rd}, 4$ th, and 5th levels; 


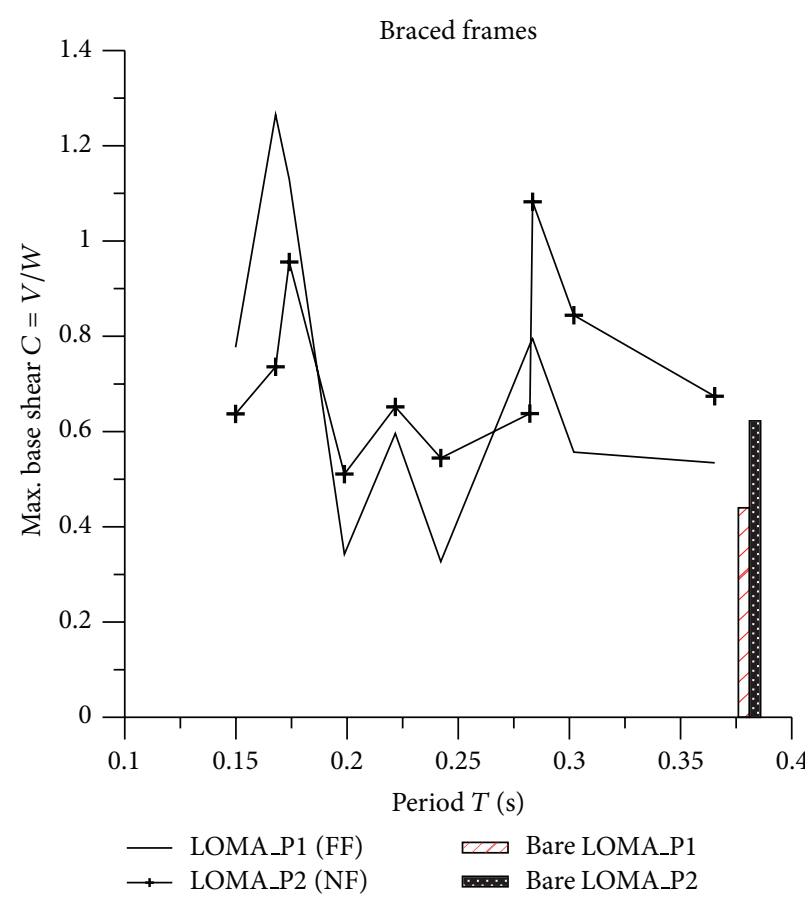

(a)

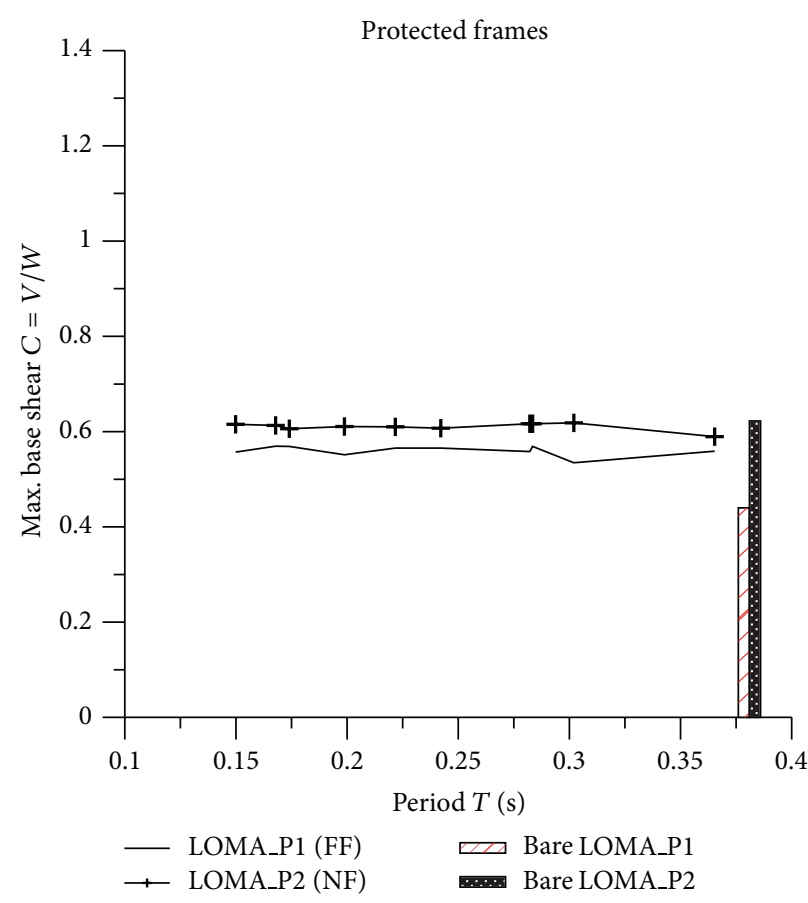

(b)

Figure 8: Maximum base shear.

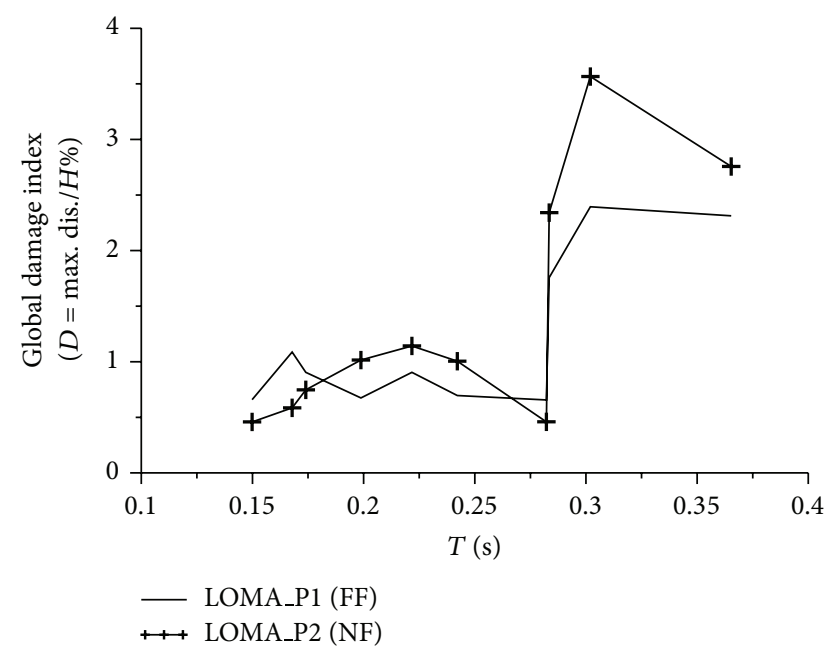

(a) Braced frames

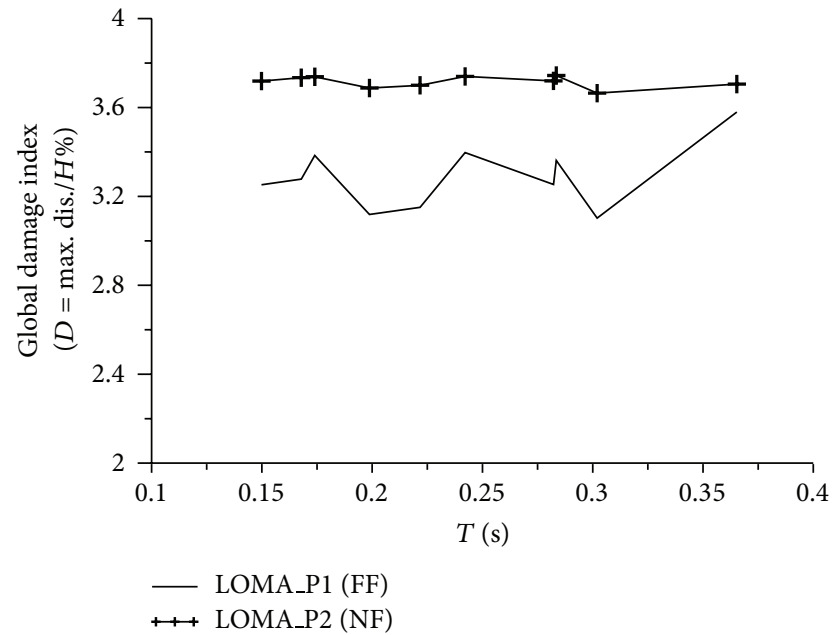

(b) Protected frames

FIGURE 9: Global damage index for (a) braced frames and for (b) protected frames.

case 9 at the 4 th and 5 th levels;

case 10 at the $3 \mathrm{rd}, 4$ th, and 5 th level.

That means that the acceleration amplifications are higher for frames subjected to far-field ground motions especially for low periods $(T=0.15-0.168 \mathrm{~s})$.

Protected Frames. The higher values of the response amplification are always obtained for frames subjected to the near-field ground motion, LOMA_P2.
Comparing the response amplification for the bare frames, the higher values are obtained under the LOMA_P2 input (near-field ground motion).

(vi) Energy Dissipation. The maximum energy dissipation produced by the friction dampers is obtained for frames subjected to the far-field ground motion LOMA_P1 if compared to the same case models subjected to the near-field input, LOMA_P2.

In Figure 10 the maximum acceleration amplification for the braced frames and for the protected frames is shown. 

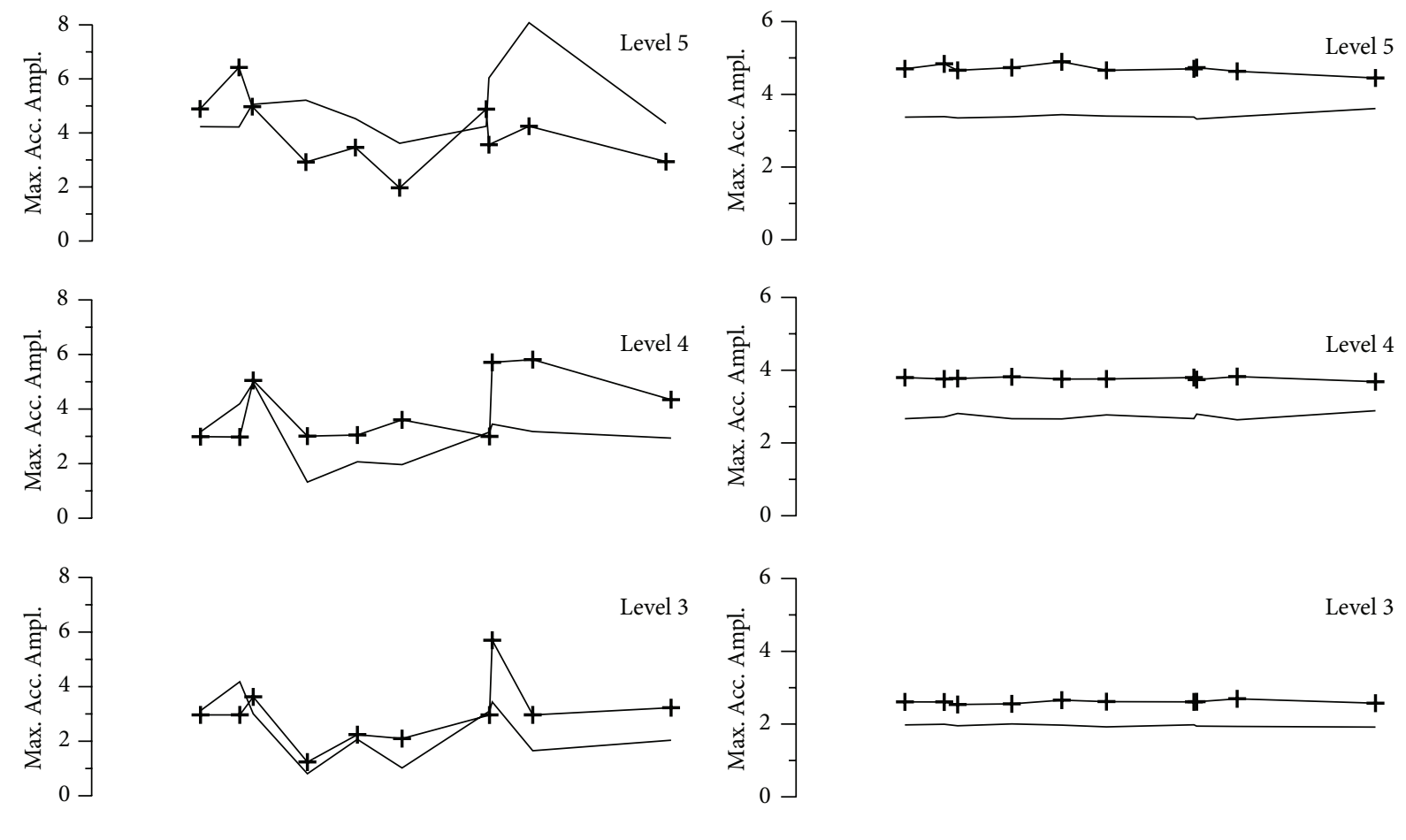

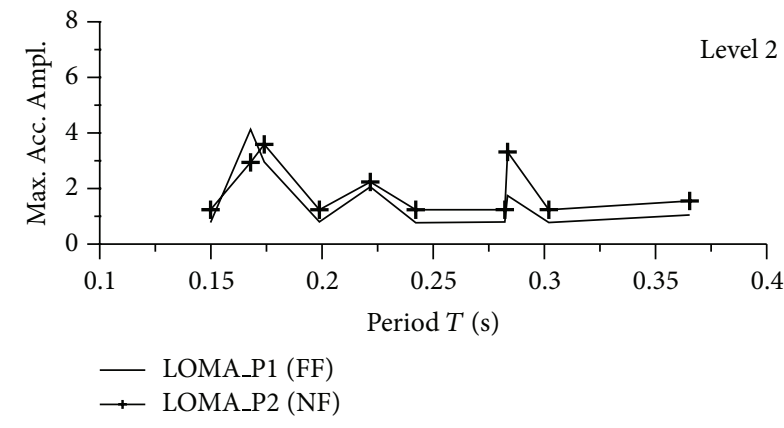

(a) Braced frames

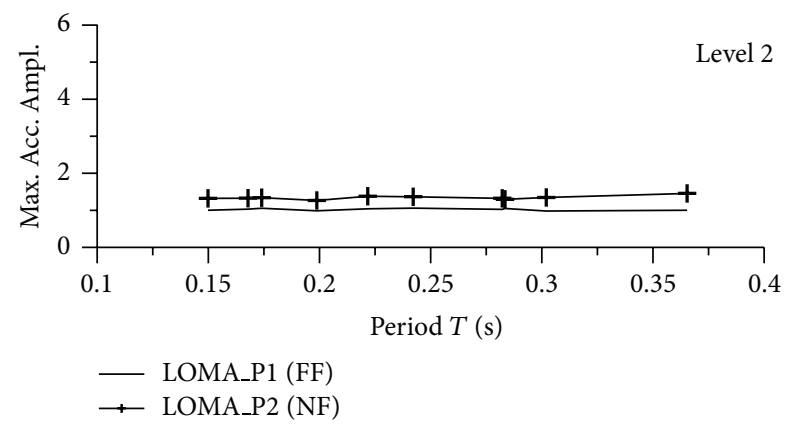

(b) Protected frames

FIgURE 10: Maximum acceleration amplification for (a) braced frames and for (b) protected frames.

In Table 2 the reduction obtained in the protected frames with respect to the braced ones is shown. The reduction has been determined (in percentage) on the maximum acceleration amplification at the 5 th level and on the maximum base shear. The sign "-" indicates that there has been an increment of the value in the protected frames.

From all the results described in this section it appears that cases 6 and 8 (low period frames) have a better response to near-field ground motion. The response is even better if these frames are protected with energy dissipaters (see Table 2).

\section{Conclusions}

A steel model of a five-level structure has been analysed. Two braces have been installed in the frame in different positions, so that ten different period models have been obtained. The structure has been numerically excited by a far-field and a near-field register. The signals have been scaled with respect to the maximum acceleration registered in the far-field area $\left(401.5 \mathrm{~cm} / \mathrm{s}^{2}\right)$. Each model has been then supposed to be equipped with friction energy dissipaters in substitution of the diagonals.

The responses to these two registers of Loma Prieta 1989 earthquake (Lick Observatory $90^{\circ}$ record (LOMA_P1) and Bolsa Rd. $90^{\circ}$ record (LOMA_P2)) of the ten models with and without dissipaters have been analysed and compared.

If protected and nonprotected systems are compared, results (max. acceleration) show that in both cases of farfield and near-field earthquakes the response of protected frames is reduced with respect to the corresponding braced frames, except for cases 4,7 , and 8 (the last only for near-field frames). A possible explanation is that the protected frames are slightly more flexible than the braced ones and cases 4,7 , and 8 present a fundamental frequency in correspondence of a peak of the response spectrum; as a result an amplification is evident. Moreover, the second periods are not negligible and could increase the global response of the frames. 
TABLE 2: Reduction obtained in protected frames with respect to braced frames.

(a) LOMA_P1

\begin{tabular}{|c|c|c|c|c|c|c|c|c|c|c|}
\hline Frames & Case 1 & Case 2 & Case 3 & Case 4 & Case 5 & Case 6 & Case 7 & Case 8 & Case 9 & Case 10 \\
\hline $\begin{array}{l}\text { Max. Ampl. } \\
\text { 5th level [\%] }\end{array}$ & 25.72 & 7.72 & 5.07 & -23.63 & 5.97 & 40.75 & -59.37 & 52.50 & 38.17 & 40.77 \\
\hline $\begin{array}{l}\text { Max. base } \\
\text { shear [\%] }\end{array}$ & 3.98 & 5.10 & 28.42 & -4.58 & -60.89 & 28.33 & -72.87 & 55.01 & 49.63 & 28.72 \\
\hline
\end{tabular}

(b) LOMA_P2

\begin{tabular}{|c|c|c|c|c|c|c|c|c|c|c|}
\hline Frames & Case 1 & Case 2 & Case 3 & Case 4 & Case 5 & Case 6 & Case 7 & Case 8 & Case 9 & Case 10 \\
\hline $\begin{array}{l}\text { Max. Ampl. } \\
\text { 5th level [\%] }\end{array}$ & 44.31 & 13.49 & 25.17 & -3.27 & 13.12 & 1.05 & -22.66 & -1.40 & 14.51 & 0.69 \\
\hline $\begin{array}{l}\text { Max. base } \\
\text { shear [\%] }\end{array}$ & 26.76 & 6.41 & 43.04 & 12.57 & -19.57 & 3.42 & -11.53 & 16.71 & 36.62 & 3.32 \\
\hline
\end{tabular}

If only the corresponding protected frames subjected to the two ground motions are compared, the response of the structures subjected to near-field ground motions is higher and the energy dissipated by the nonlinear devices is lower if compared to the frames under far-field ground motions.

In this regard, in terms of design, the position proposed in Frame 1 is not recommended since the devices are placed where the displacements that activate the friction in the dissipators, that is the energy dissipation, are minimum (first level). Instead, the arrangement presented in Frame 3 is suggested as the drift recorded at that level allows maximum displacements and thus dissipation of energy.

It must be noticed that the response of the protected frames is very soft without sharp differences among the frames. It has also been noted that the effectiveness of the dissipators does not depend on the fundamental period of the frames because the maximum base shear keeps constant for different types of frames (this is reasonable given that when the displacement between the two parts of the dissipator is activated, the frames take the same structural behavior/model regardless of the location of the devices). In contrast, in the braced frames there are considerable differences depending on the frame considered, clear sign of a strong dependence of the structural response on the intrinsic characteristics of the structure and the seismic signal (for both near-field and far-field signals).

In addition, the maximum base shear is almost always reduced in the protected frames with respect to the corresponding braced frames, also when subjected to the near-field ground motion. It is even lower than the base shear obtained for the bare frame under the same near-field ground motion. One possible explanation may be found in the particular form of the response spectra that enhance the low periods of the protected frames compared to the bare frames. It seems that regarding the protected frames the behavior under near-field motions is better than under far-field ones.

Comparing the near-field and far-field responses, the following could be affirmed.

(i) Braced frames, cases 6, 8, 9, and 10 under near-field ground motions have better behaviour with respect to the same cases under a far-field ground motion; in fact, the spectral acceleration in the range [0.15-0.2 s] is lower in near-field spectrum.

(ii) Protected frames under near-field ground motions always show higher responses with respect to the frames in far-field areas.

Probably this is due again to a slight shift of the period towards values of the response amplification that are lower for far-field ground motions with respect to the near-field ones.

Moreover, it is possible to notice that the shape and the values of the interstory drifts in case 4 subjected to LOMA_P2 (near-field) are quite the same for the braced and the protected frames. That is principally due to higher excitation at high frequencies produced by far-field ground motions.

In any case for buildings under far-field motions the efficacy of the friction devices is obtained for cases 6, 8, and 9 (lower period frames). For frames under near-field motions the efficacy of the dissipaters is principally obtained in cases 1 and 3 (higher period frames). In fact, for higher period, around $0.3 \mathrm{~s}$, the far-field response spectrum for Lick Observatory $90^{\circ}$ record shows very low values, so that the dissipaters do not provide a high reduction and, consequently, their efficacy is reduced. This confirms that dissipators should be installed in the position of higher displacements to effectively reduce high quantity of the seismic energy.

\section{Conflict of Interests}

The author declares that there is no conflict of interests regarding the publication of this paper.

\section{References}

[1] G. P. Mavroeidis and A. S. Papageorgiou, "A mathematical representation of near-fault ground motions," Bulletin of the Seismological Society of America, vol. 93, no. 3, pp. 1099-1131, 2003.

[2] A. Moustafa and I. Takewaki, "Deterministic and probabilistic representation of near-field pulse-like ground motion," Soil 
Dynamics and Earthquake Engineering, vol. 30, no. 5, pp. 412422,2010

[3] B. Alavi and H. Krawinkler, "Behavior of moment-resisting frame structures subjected to near-fault ground motions," Earthquake Engineering and Structural Dynamics, vol. 33, no. 6, pp. 687-706, 2004.

[4] R. S. Jalali, M. D. Trifunac, G. Ghodrati Amiri, and M. Zahedi, "Wave-passage effects on strength-reduction factors for design of structures near earthquake faults," Soil Dynamics and Earthquake Engineering, vol. 27, no. 8, pp. 703-711, 2007.

[5] J. D. Bray and A. Rodriguez-Marek, "Characterization of forward-directivity ground motions in the near-fault region," Soil Dynamics and Earthquake Engineering, vol. 24, no. 11, pp. 815-828, 2004.

[6] F. Mazza and M. Mazza, "Nonlinear modeling and analysis of R.C. framed buildings located in a near-fault area," The Open Construction \& Building Technology Journal, vol. 6, pp. 346-354, 2012.

[7] J. J. Bommer, G. Georgallides, and I. J. Tromans, "Is there a nearfield for small-to-moderate magnitude earthquakes?" Journal of Earthquake Engineering, vol. 5, no. 3, pp. 395-423, 2001.

[8] A. K. Chopra and C. Chintanapakdee, "Comparing response of SDF systems to near-fault and far-fault earthquake motions in the context of spectral regions," Earthquake Engineering \& Structural Dynamics, vol. 30, no. 12, pp. 1769-1789, 2001.

[9] G. P. Mavroeidis, G. Dong, and A. S. Papageorgiou, "Near-fault ground motions, and the response of elastic and inelastic singledegree-of-freedom (SDOF) systems," Earthquake Engineering \& Structural Dynamics, vol. 33, no. 9, pp. 1023-1049, 2004.

[10] A. K. Chopra and C. Chintanapakdee, "Drift spectrum vs. modal analysis of structural response to near-fault ground motions," Earthquake Spectra, vol. 17, no. 2, pp. 221-234, 2001.

[11] J. F. Hall, "Seismic response of steel frame buildings to nearsource ground motions," Earthquake Engineering \& Structural Dynamics, vol. 27, no. 12, pp. 1445-1464, 1998.

[12] A. Filiatrault, R. Tremblay, and A. Wanitkorkul, "Performance evaluation of passive damping systems for the seismic retrofit of steel moment-resisting frames subjected to near-field ground motions," Earthquake Spectra, vol. 17, no. 3, pp. 427-456, 2001.

[13] W. J. Yi and B. Zhang, "Damage mechanism of frame structures under action of near-field earthquake," Journal of Natural Disasters, vol. 16, no. 2, pp. 112-117, 2007.

[14] C. E. Grigorian, T.-S. Yang, and E. P. Popov, "Slotted bolted connection energy dissipators," Tech. Rep. UCB/EERC-92/10, Earthquake Engineering Research Center, University of California at Berkeley, 1992.

[15] D. Foti, L. M. Bozzo, and F. Lopez-Almansa, "Numerical efficiency assessment of energy dissipators for seismic protection of buildings," Earthquake Engineering and Structural Dynamics, vol. 27, no. 6, pp. 543-556, 1998.

[16] D. Foti, L. M. Bozzo, and F. Lopez-Almansa, "Numerical efficiency assessment of energy dissipators for seismic protection of buildings," in Proceedings of the International Conference on the Application of Artificial Intelligemce to Civil and Structural Engineering (AICIVIL-COMP '99), vol. 3, pp. 175-186, Oxford, UK, September 1999.

[17] L. Tirca, D. Foti, and M. Diaferio, "Response of middle-rise steel frames with and without passive dampers to near-field ground motions," Engineering Structures, vol. 25, no. 2, pp. 169179, 2003.
[18] D. Foti, M. Diaferio, and R. Nobile, "Dynamic behavior of new aluminum-steel energy dissipating devices," Structural Control and Health Monitoring, vol. 20, no. 7, pp. 1106-1119, 2013.

[19] D. Ordoñez, D. Foti, and L. M. Bozzo, "Comparative study of the inelastic structural response of base isolated buildings," Earthquake Engineering \& Structural Dynamics, vol. 32, no. 1, pp. 151-164, 2003.

[20] A. K. Agrawal, Z. Xu, and W. L. He, "Ground motion pulsebased active control of a linear base-isolated benchmark building," Structural Control and Health Monitoring, vol. 13, no. 2-3, pp. 792-808, 2006.

[21] W.-L. He and A. K. Agrawal, "Analytical model of ground motion pulses for the design and assessment of seismic protective systems," Journal of Structural Engineering, vol. 134, no. 7, pp. 1177-1188, 2008.

[22] D. Foti, M. Diaferio, and R. Nobile, "Optimal design of a new seismic passive protection device made in aluminium and steel," Structural Engineering and Mechanics, vol. 35, no. 1, pp. 119-122, 2010.

[23] D. Foti, O. Caselles, and J. Canas, "Experimental tests of a reduced scale model seismically protected with energy dissipators: preliminary design," in Proceedings of the 7th International Conference on "Computing in Civil and Building Engineering" (ICCCBE '97), pp. 1315-1320, Seoul, Republic of Korea, August 1997.

[24] D. Foti, O. Caselles, and J. Canas, "Shaking table tests on a reduced scale model seismically protected with friction energy dissipators," in Proceedings of the 4th International Conference on the European Association for Structural Dynamics, pp. 575580, Praga, Poland, June 1999.

[25] E. L. Wilson, SADSAP (Static and Dynamic Structural Analysis Programs), Structural Analysis Programs, 1992.

[26] International Building Code (IBC), International Code Council, International Building Code (IBC), Washington, DC, USA, 2009. 

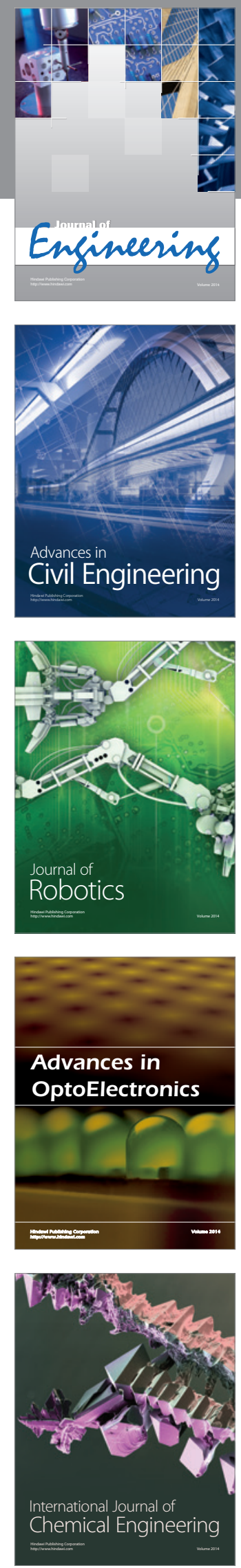

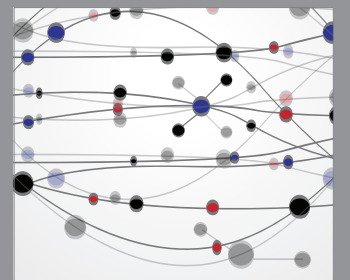

The Scientific World Journal
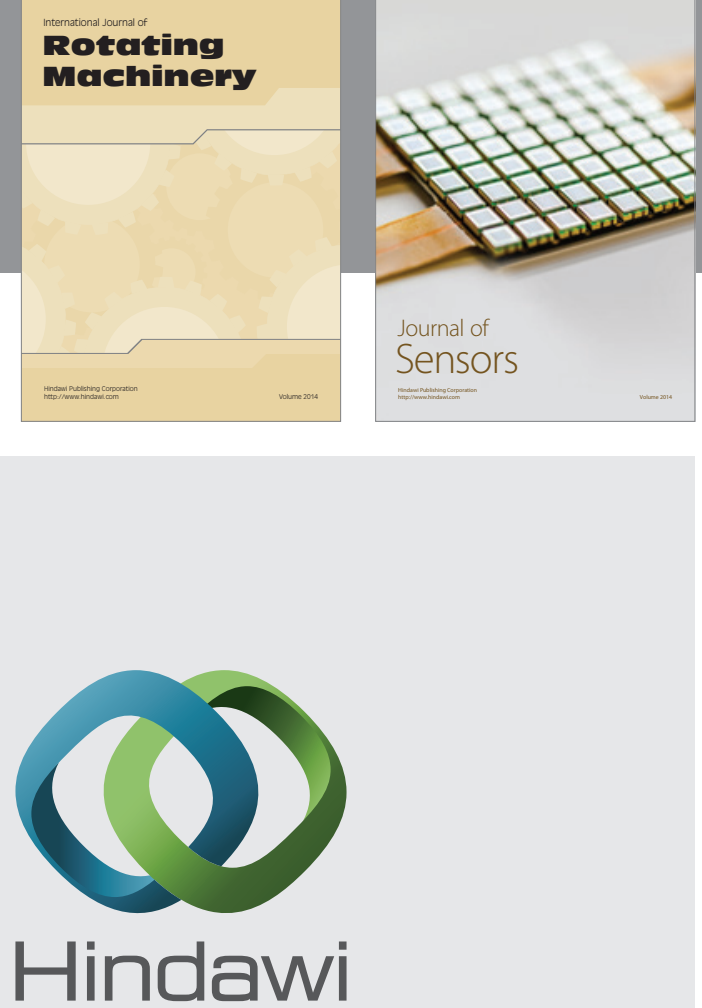

Submit your manuscripts at http://www.hindawi.com
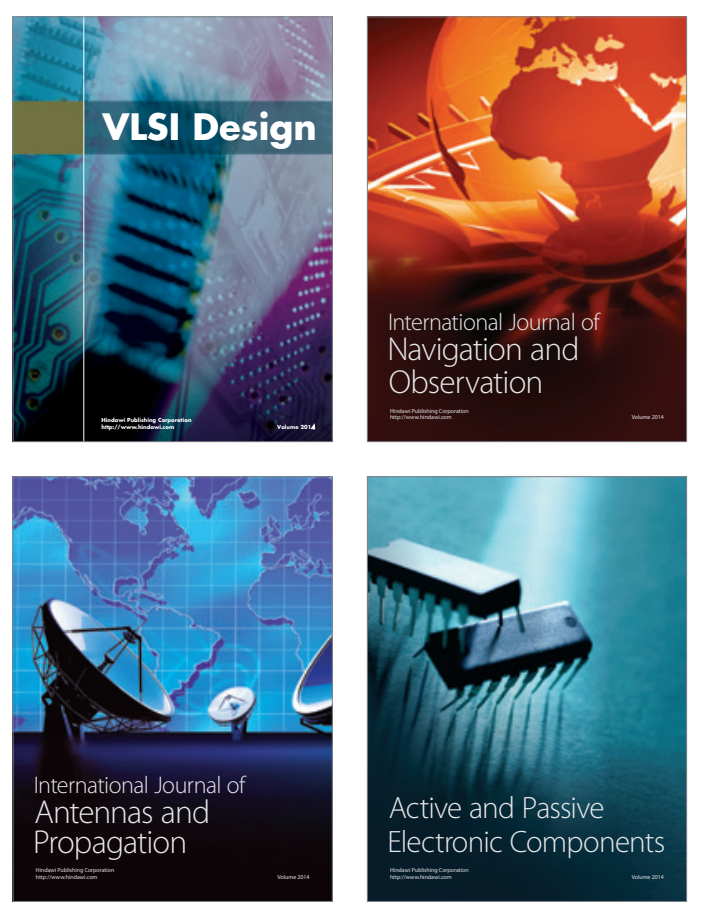
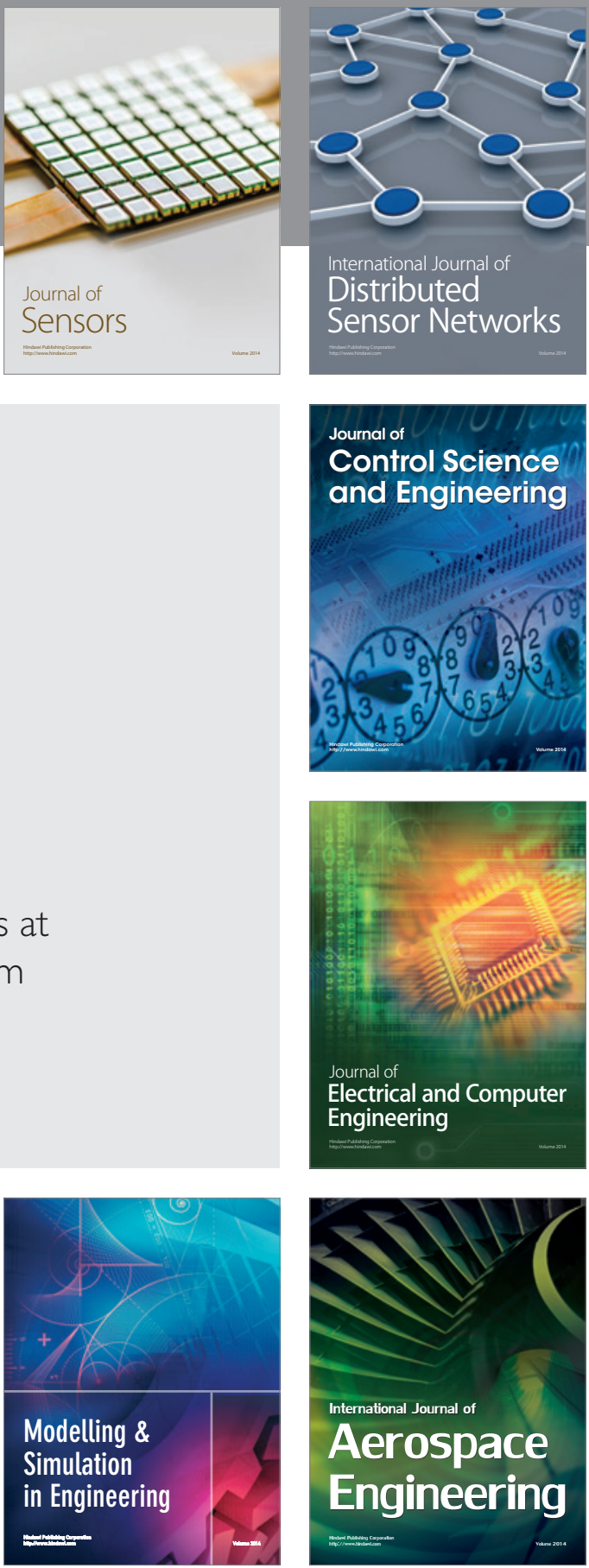

Journal of

Control Science

and Engineering
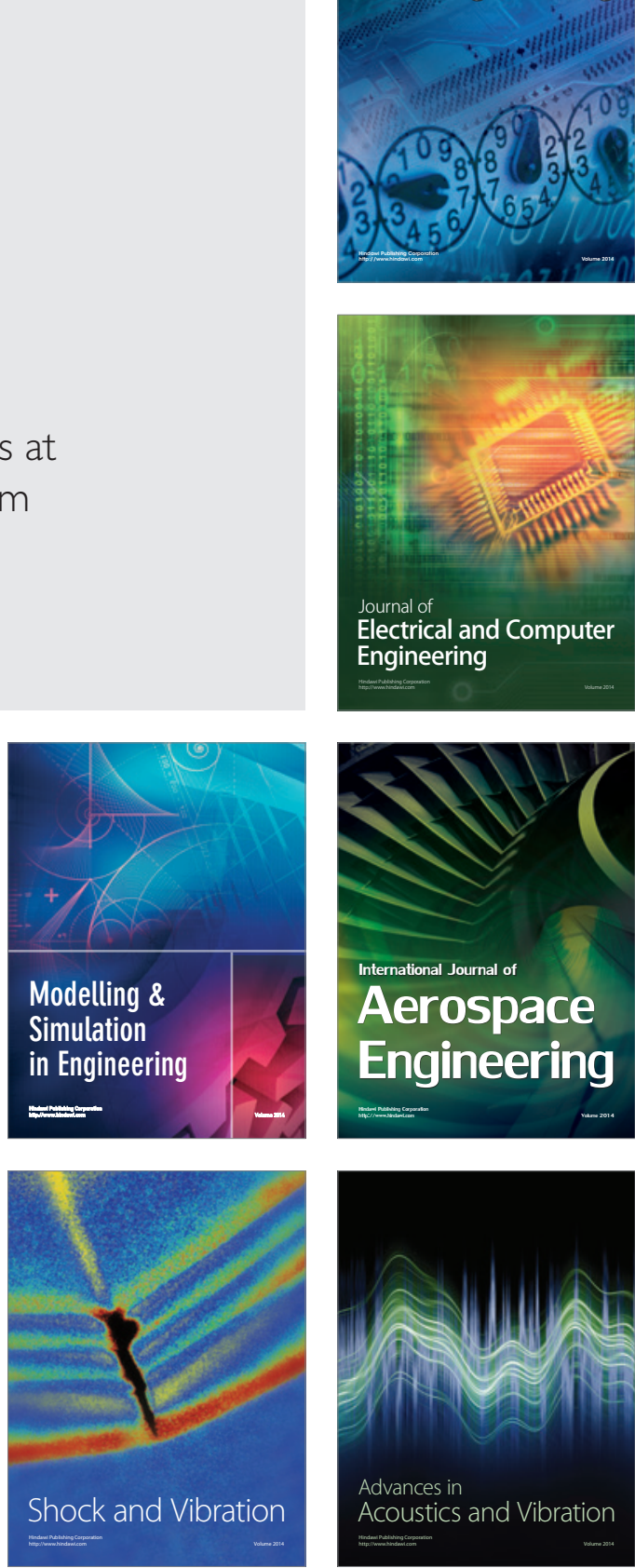